\section{Original Research}

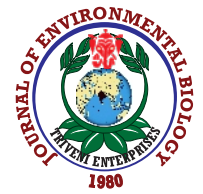

DOI : http://doi.org/10.22438/jeb/41/2(SI)/JEB-16

Journal Home page : www.jeb.co.in ^ E-mail : editor@jeb.co.in Journal of Environmental Biology

\title{
Influence of meteorological factors on ecological conditions of the atmosphere in Tbilisi, Georgia
}

\author{
L. Lagidze $e^{1 *}$, L. Matchavariani ${ }^{2}$, D. Svanadze $e^{3}$ and G. Khomasuridze ${ }^{4}$ \\ 'Department of Nature Management, Faculty of Exact and Natural Sciences, Tbilisi State University, Tbilisi, 0179 Georgia \\ ${ }^{2}$ Department of Soil Geography, Faculty of Exact and Natural Sciences, Tbilisi State University, Tbilisi, 0179, Georgia \\ ${ }^{3}$ GIS-Lab, Faculty of Social \& Political Sciences, Tbilisi State University, Tbilisi, 0179, Georgia \\ ${ }^{4}$ Department of Geography, Faculty of Exact and Natural Sciences, Tbilisi State University, Tbilisi, 0179, Georgia \\ *Corresponding Author Email : lamzira.laghidze@tsu.ge
}

\begin{abstract}
Aim: Establishment of anthropogenic aerosols change dynamics in the atmosphere of Tbilisi city, their distribution, concentration, under complex orographic and climate conditions.

Methodology: For the assessment of climate change for Tbilisi city, air pollution monitoring materials were used from the National Environmental Agency where observation was carried out for the background air pollution and also concentrations of aerosols and harmful substances were measured in automatic mode. The results of four stages of indicator were presented. Statistical, climatic and graphical analysis were used for research.
\end{abstract}

Results: The basic pollutants: (carbon dioxide, sulfur dioxide, nitrogen oxides, ozone, $\mathrm{PM}_{2.5}$ and $\mathrm{PM}_{10}$ (monthly and annual concentrations) in most cases, exceeded MPC. Nitrogen oxides and ground ozone were particularly sensitive, average annual concentrations was 1.4-1.8 times and exceeded the MPC, which affected the health of the population. It is noteworthy, that for last 5 years in Tbilisi, average annual concentration of lead decreased. Climate change expression often have a complex character, which especially complicates the determination of causal relationship between them and requires right approach and proper definition of adaptation measure.

Interpretation: Meteorological elements play an important role in aerosol's accumulation in the atmosphere. There was a correlation between meteorological elements and atmosphere polluting ingredients. Pollutants concentration on the surface layer frequently exceeded MPC, i.e., promoted by physical-geographic state and meteo-climate conditions due to which urban microclimate change is possible.

Key words: Atmospheric pollution, Climate change, Meteorological conditions, Tbilisi city

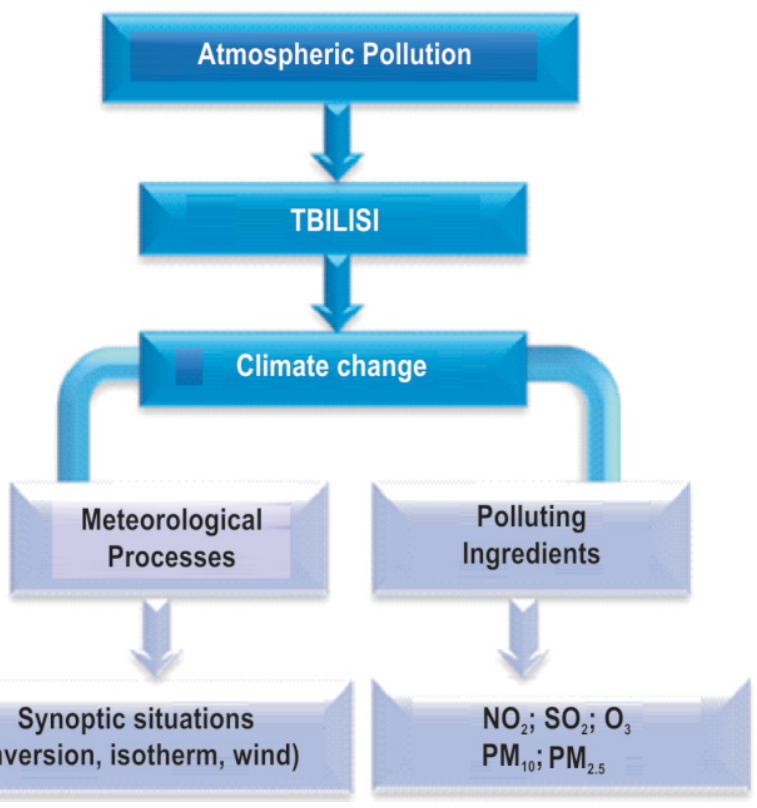

How to cite : Lagidze, L., L. Matchavariani, D. Svanadze and G. Khomasuridze: Influence of meteorological factors on ecological conditions of the atmosphere in Tbilisi, Georgia. J. Environ. Biol.,41, 391-395 (2020). 


\section{Introduction}

Atmosphere as a main component of the environment has experienced significant changes from the second part of $20^{\text {th }}$ century due to anthropogenic factors that caused global climate changes. Climate change is often complex in nature that makes cause-and-effect relationship extremely sophisticated (Atlas of Atmospheric Pollution of the World, 2011). Despite global nature of climate changes, its influence is characterized by a local specificity according to various regions, geographic locations and climate characteristics (Matchavariani and Lagidze, 2012).

The change in ecological equilibrium is noticeable due to anthropogenic factors, intensive growth and development of cities, urbanization process, deforestation etc (Main,1981). Significant impacts on climate change can be attributed to the cities that changes radiation, temperature, humidity and wind regime to some extent. On the one hand, the city is a "heat island" that promotes the emergence of local convective, ascending and descending currents, on the other hand, fog (often due to contamination) is often present in the city, which prevents the spread of pollutants. The issues of atmospheric history (Brimblecombe and Sturges, 2009), climatic features and effects on the environment (Atalay, et al., 2014; Curebal and Efe, 2014) as well as air pollution and quality (Schultz et al., 2003; Mickley and Jacob, 2004; Jacob and Winner, 2009; Efe et al., 2014; Fenger, 2009; De Sario et al., 2013) has been reported by researchers.

"Heat island" is of complicated structure, and due to city peculiarities urban pollution level is significant when pollution reaches a critical point. Substantial part of aerosol is formed in the cities resulting from emission of solid and liquid particles (from enterprises, heating systems, transport etc.). High concentration of aerosol particles in the air results in smog(Amiranashvili et al., 2012). Along with climate changes, the extreme weather events are frequent and stronger. Intensification of some of these events are related to change in global climate.

In addition to intensive environmental pollution, especially in big cities, significant change in meteo-geophysical parameters have also taken place. Addition anthropogenic load on the biosphere has increased the level of risk-factors related to human health and life.

As climate change is linked with both natural processes and anthropogenic factors, due to their combined action the admixtures of different origin and density enters the atmosphere and hydrosphere. Aerosols remains in the atmosphere for longer duration and their distribution in the atmosphere depends on the vertical distribution of admixture density due to complex physicalgeographical and microclimate peculiarities (Georgia's Second, 2009 and Third, 2015 National Communications to the UNFCCC).
The aim of this study was to establish the impact of aerosols anthropogenic origin on the atmosphere of Tbilisi city, their spatial and time distribution, propagation and concentration, and meteorological processes (atmosphere circulation, temperature, wind, cloudiness, humidity, inversion, fog etc.), under complex orographic and climate conditions.

\section{Materials and Methods}

While studying Tbilisi atmospheric air state, we took into account geographic location of the city: both low-mountain and moderately mountainous, and plain and undulating reliefs appeared within the limits of the city. There were humid, semihumid and semi-arid landscapes that were related to moderately humid subtropical, dry subtropical and moderately humid climate. Flood-plain forests that have continuous character were peculiar for Mtkvari river valley. Natural vegetation of the city belonged to 13 types of ecosystems - starting with humid forests and ended with semi-desert semi-arid vegetation.

For the assessment of climate changes in Tbilisi City, the Georgian National Environmental Agency's 2018 years atmospheric air pollution monitoring materials with observations over background air pollution and measurement of concentrations of aerosols and harmful substances in automatic mode were used. The concentrations of $\mathrm{PM}_{10}, \mathrm{PM}_{2.5}$, carbon oxide, sulfur dioxide, nitrogen oxide and dioxide, NOX and ozone were estimated city wide.

Statistical, climatologic and graphical analyses were carried out. Data processing was based on the method of multifactorial statistical analyses (Nikolaishvili, 2014).

\section{Results and Discussion}

Aerosols are non-uniformly distributed in Tbilisi. Among meteorological processes, the atmosphere circulation is essential, during which aerosols are propagated in both horizontal and vertical directions. Aerosol transport intensity depends on relief, meteorological conditions and atmosphere stratification.

Dissipation and diffusion of aerosols formed by different sources occur quite intensely through turbulent mixing peculiar for ground air. In this case, aerosols are dissipated and their concentration becomes low depending on atmosphere stratification. It is obvious that duration and repetition of meteorological conditions cause acute air pollution compared to the cities that are characterized by relatively shorter duration and less repetition of elemental meteorological phenomena.

Complex terrain and meteorological conditions of Tbilisi substantially change the general characteristics of atmospheric circulation that predetermines complicated conditions of aerosol propagation. Duration of aerosol availability in the atmosphere is 
significantly influenced by the character of vertical profile of various meteorological elements (temperature, wind, humidity), and steady state of atmosphere is especially important.

Study of correlation relationship between separate polluting ingredients and meteorological parameters in Tbilisi showed a positive correlation between $\mathrm{SO}_{2}, \mathrm{CO}, \mathrm{NO}_{2}$ (Lagidze et al., 2005, 2015). For carbon dioxide, negative correlation dependence with wind velocity was observed. CO concentration lowers, when the winds of northern or north-west directions increase, while in case of winds of eastern or south-east directions, $\mathrm{CO}$ concentration rises. A negative correlation exist between $\mathrm{CO}$ and temperature. In winter season, $\mathrm{CO}$ reaches maximum value due to ground inversions. $\mathrm{CO}$ is in the negative correlation relationship with humidity, as well. $\mathrm{SO}_{2}$ and $\mathrm{NO}_{2}$ correlation with temperature is positive due to absorption of UV rays and transmission of infrared radiation by these gases. As a result, in case of interrelation between polluting ingredients and meteorological situation for Tbilisi, five types of surface meteorological situation promoting aerosols accumulation were established: anticyclone; saddle-like (low-gradient baric field); Easterly oriented high-pressure ridge; Occluded cyclone and Occlusion front (Gunia et al., 2009).

The mentioned meteorological situations, in addition to differences, have variety of common features that are characterized by low gradients and descending air current, in such case turbulence is minimal and as a consequence ground inversion takes place.

Studies have shown that during cold season in Tbilisi the most characteristic synoptic situation when total pollution is increasing is high-pressure tray, related mainly with stationary anticyclones in Kazakhstan, West Siberia or East Siberia. During anticyclone, total air pollution in the atmosphere is $13 \%$. Anticyclone is characterized by descending currents, clear weather and strong radiational cooling (at night and during daylight hours), which is a contributing factor to surface inversion. Under these conditions, the increase in air pollution is caused by the transport of vehicles and accumulation of emissions in the lower layer of the troposphere (due to the existence of an inverted layer, the movement of aerosols in the free atmosphere is limited).

Atmospheric pollution slightly increases (by 9\%) in lowgradient baric field (baric saddle); the mentioned meteorological situation was peculiar for cold season; at this time frontal part passage in the rear of a cyclone is accompanied by precipitation.

During warm season, the relationship between total pollution and meteorological situation differs from that of cold season. For instance, high-pressure ridge is rare in warm seasons; pollution level increases by $36 \%$ in case of low-gradient baric field (baricsaddle), by $21 \%$ during occlusion front, $18 \%$ in case of anticyclone baric field and $14 \%$ during low-pressure field.
Environment pollution degree in Tbilisi was established by means of fixed observation points over atmospheric air and expeditions. Average annual concentrations registered at automatic stations are given in the tabular form (Table 1).

The results of Tbilisi atmospheric air monitoring are as follows:

Tsereteli avenue: The average annual concentration of nitrogen dioxide was $0.058 \mathrm{mg} \mathrm{m}^{-3}$, and it increased 1.5 times the corresponding maximum permissible limit, whereas the level of nitrogen oxide was $0.085 \mathrm{mg} \mathrm{m}^{-3}$.

Kazbegi avenue: The average annual concentration of ozone was $0.041 \mathrm{mg} \mathrm{m}^{-3}$; exceeded 1.4 times the corresponding maximum permissible limit.

Varketili: The average annual concentration of ozone was 0.05 $\mathrm{mg} \mathrm{m}^{-3}$ and exceeded 1.8-times the corresponding maximum permissible limit.

The automatic stations air monitoring materials revealed that average annual concentrations of different kinds of pollutants at all points was within the permissible limit.

Distribution of monthly average concentration of pollutants for Tbilisi is presented in (Fig. 1). According to the data of National Environmental Agency's automatic measuring stations, the concentration of pollutants increased from October to April, especially high pollution $\left(\mathrm{NO}_{2}, \mathrm{NO}, \mathrm{SO}_{2}\right)$ was noted on TsereteliAvenue. The average annual concentration of $\mathrm{PM}_{10}$ at Tsereteli Avenue, Kazbegi Avenue and Varketili was compared to $24 \mathrm{hr}$ MPC $\left(0.05 \mathrm{mg} \mathrm{m}^{-3}\right)$ and also to annual permissible concentration $\left(0.04 \mathrm{mg} \mathrm{m}^{-3}\right)$ standards set by the European Union.

All round the year, the $\mathrm{PM}_{10}$ value at Tsereteli Avenue exceeded 10-times the normal value (212 days a year) and the highest concentration of $0.165 \mathrm{mg} \mathrm{m}^{-3}$ was registered on $17^{\text {th }}$ January and exceeded 3.3 times the MPC value. At Kazbegi Avenue, increased concentrations were registered during 86 days: maximum was recorded on $7^{\text {th }}$ September, when $\mathrm{PM}_{10}$ content reached 0.139 , while in Varketili exceedance of $\mathrm{PM}^{10}$ concentration was registered on 85 days and the maximum value of on18th of January was 2.6 times higher than the permissible limit. The average annual value of $\mathrm{PM}_{10}$, exceeded MPC standards 1.5 times at Tsereteli Avenue, is insignificantly higher at Kazbegi Avenue and did not exceed the MPC standards in Varketili.

The concentration of $\mathrm{PM}_{2.5}$ was also compared with the annual permissible limit $\left(0.025 \mathrm{mg} \mathrm{m}^{-3}\right)$ established by the European Union. The $\mathrm{PM}_{2.5}$ level at Kazbegi and Varketili Avenue did not exceed the normal value, while at Tsereteli Avenue insignificant increase was registered. 
Table 1 : Average annual concentrations of different kinds of pollutants $\left(\mathrm{mg} \mathrm{m}^{-3}\right)$

\begin{tabular}{lllllllll}
\hline Observation station & $\mathrm{PM}_{10}$ & $\mathrm{PM}_{2.5}$ & $\mathrm{NO}_{2}$ & $\mathrm{NO}$ & $\mathrm{NOx}$ & $\mathrm{CO}$ & $\mathrm{SO}_{2}$ & $\mathrm{O}_{3}$ \\
\hline Tsereteli avenue & 0.058 & 0.026 & 0.058 & 0.085 & 0.0143 & 1.0 & 0.024 & 0.027 \\
Kazbegi avenue & 0.041 & 0.018 & 0.037 & 0.020 & 0.020 & 0.5 & 0.006 & 0.041 \\
Varketili & 0.039 & 0.020 & 0.029 & 0.017 & 0.017 & 0.5 & 0.008 & 0.055 \\
\hline
\end{tabular}

Researches show that the random concentration values of $\mathrm{PM}_{2.5}$ particles were not high and were satisfactory. But we took into account that $\mathrm{PM}_{2.5}$ particles were of small size and, therefore, light-weight. As a result, they were in suspended state in the atmosphere due to low sedimentation rate i.e., 10 times lower compared to $\mathrm{PM}_{10}$ particles. As a result, $\mathrm{PM}_{2,5}$ particles were characterized by clearly manifested correlation with observation time.

In total, 110 measurements were conducted in Tbilisi in four stages and on 21 points of the city. Among them, 80 measurements of nitrogen dioxide, 6 of sulfur dioxide, 12 of ozone and 12 measurements of benzene. Low levels of sulfur dioxide and ozone were registered everywhere. Nitrogen dioxide index was low only in 15 cases, average in 55, and high in 10 cases. Benzene was low in 9 cases and average in 3 cases.

Average monthly concentrations of almost all polluting agents increased citywide during cold seasons (exceed MPC in winter time), and decreased during warm season.

The main air-meteorological situation was established from the studies when the level of pollutants in the atmosphere (Tbilisi city) increased. Almost in all cases; high-pressure baric field (anticyclone); wind velocity near the earth surface was less than $5 \mathrm{~m} \mathrm{sec}^{-1}$; impact of frontal and stream currents was not indicated; wind velocity reduced even at height; turbulent mixing was feeble; inversion and isothermy occurred frequently (Gunia et al., 2009). Under the above mentioned conditions, the pollution level on the surface layer was high. It should be mentioned that the circumstance under these conditions, due to increase in aerosol concentration, the ozone concentration increases and as a result photochemical smog is formed (Amiranashvili, 2012).

Vehicular emission is the main source of air pollution, in Tbilisi. According to different researches and official documents, more than 80 percent of air pollution is due to vehicular emission, improper organization and management of road traffic, low fuel quality, technical malfunction of motor vehicles, vehicle fleet age and low level of public transport development, etc. (Lagidze et al.,2005, 2015).

Thus, the influence of meteorological conditions on atmospheric pollution was established. There was a correlation between both meteorological elements and atmosphere polluting ingredients, and in between these ingredients themselves play an important role in the accumulation of aerosol in the atmosphere.
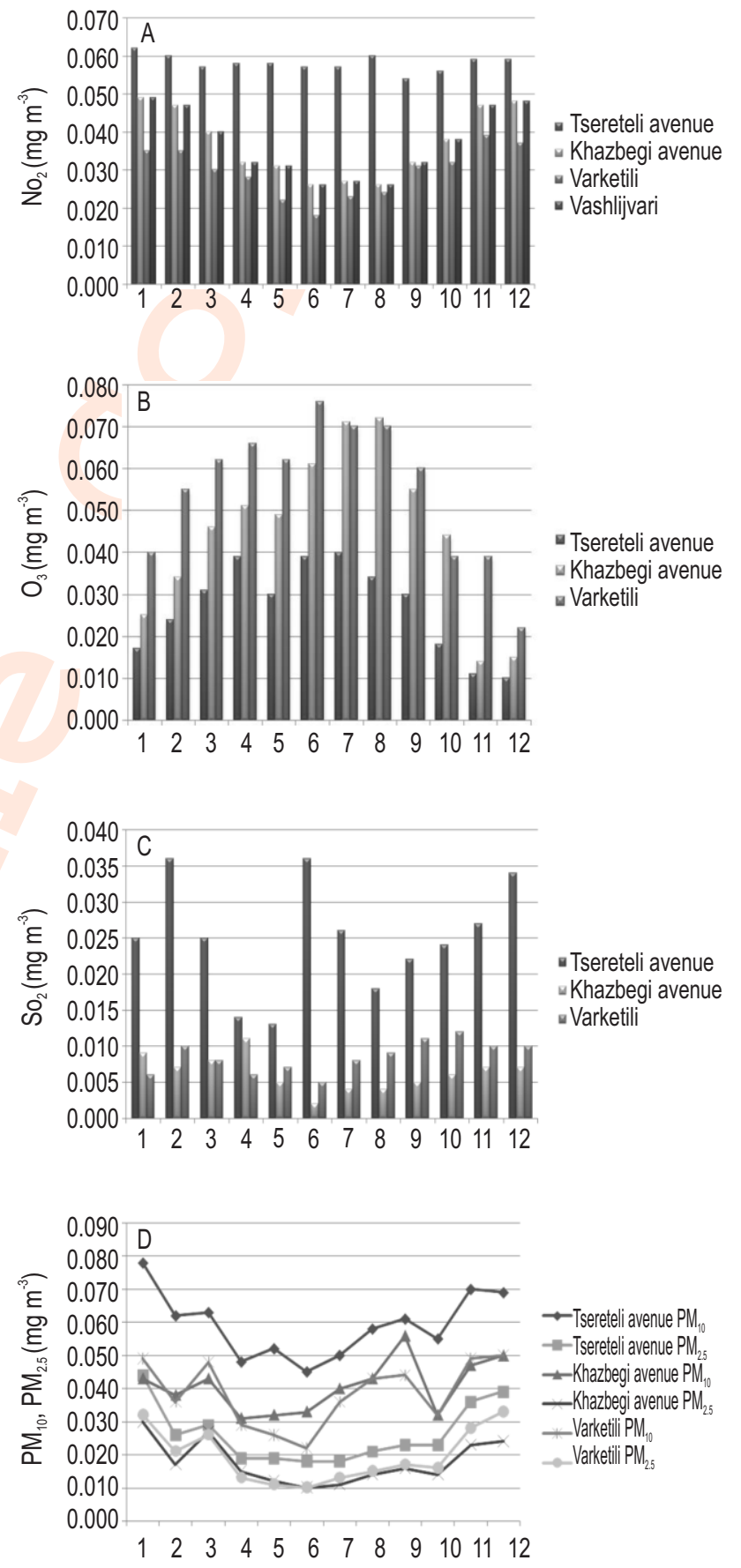

Fig.1 : Average annual concertration of $(A) \mathrm{NO}_{2} ;(B) \mathrm{O}_{3} ;(C) \mathrm{SO}_{2}$ and (D) $\mathrm{PM}_{10}, \mathrm{PM}_{2.5}$. 
High-pressure ridge, i.e., oriented from east to west (31\%) was the most characteristic meteorological situation for Tbilisi during cold season, due to which total pollution increased.

Random measurements of few substances showed that the concentration of pollutants exceeded maximum permissible limits 2-3 times. Pollutant concentration on the surface layer of Tbilisi city frequently exceeded MPC, i.e., promoted by combined physical-geographic state of Georgia (terraced structure of Tbilisi hollow, hydrographic network, vegetation cover etc.) and meteoclimate conditions due to which urban microclimate change is possible.

\section{References}

Atalay, I., R. Efe and M. Ozturk: Effects of topography and climate on the ecology of Taurus Mountains in the Mediterranean Region of Turkey. Procedia-Social Behav. Sci., 120, 142-156 (2014).

Atlas of Atmospheric Pollution of the World (2011).

Amiranashvili, A., T. Bliadze and V. Chikhladze: Photochemical smog in Tbilisi. Universal, Tbilisi (2012).

Bhola, R., L.T. Gurjar, M. Chandra and S.P. Ojha: Air Pollution (Health and Environmental Impacts). CRC Press, New York (2010).

Brimblecombe, P. and K. Sturges: History of atmospheric environment. Atmosph. Environ., 43, 2-8 (2009)

Curebal, I. and R. Efe: An overview of climatic features of the Ermenek River Basin. Proc. Soc. Behav. Sci., 120, 609-620 (2014).

De Sario, M., K. Katsouyanni and P. Michelozzi: Climate change, extreme weather events, air pollution and respiratory health in Europe. Europ. Respi. J., 42, 826-843 (2013).

Efe, R., A. Soykan, I. Curebal and S. Sönmez: Geomorphic and ecologic fundamentals of air quality in the vicinity of Kaz Mountains. Proce. Soc. Behav. Sci., 120, 524-531 (2014)

Fenger, J.: Air pollution in the last 50 years - From local to global. Atmosp. Environ., 43, 13-22 (2009)
Gunia, G. and R. Saralidze: Pollution of industrial district in conditions of paired meteorological parameters. Tbilisi: Caucasian Geographical Review, 10, 44-47 (2009).

Georgia's Second National Communications to the United Nations Framework Convention on Climate Change (UNFCCC). National Climate Research Centre, Tbilisi (2009).

Georgia's Third National Communications to the United Nations Framework Convention on Climate Change (UNFCCC).National Climate Research Centre, Tbilisi (2015).

Jacob, D.J. and D.A. Winner: Effect of climate change on air quality. Atmosp. Environ., 43, 51-63 (2009).

Lagidze, L., N. Khidasheli, S. Siordia and N. Motsonelidze: Medical assessment of weather in accordance with meteorological, climate and ecological factors. Tbilisi, Cauc. Geogr. J., 5, $36-39$ (2005).

Lagidze, L., N. Khidasheli, S. Siordia and N. Motsonelidze: Medical assessment of weather in accordance with meteorological, climate and ecological factors. Tbil. Cauc. Geogr. J., 5, 36-39 (2005).

Lagidze, L., L. Matchavariani, N. Tsivtsivadze, N. Khidasheli, N. Paichadze and N. Motsonelidze: Medical aspects of atmospheric pollution. J. Environ. Biol., 36, 101-107 (2015).

Main, N.: Integrated monitoring concentrations and their use in climate monitoring systems projecting. Leningrad: Proceedings of $2^{\text {nd }}$ International Symposium on global integrated monitoring, pp. 5761 (1981).

Matchavariani, L. and L. Lagidze: Environment transformation in Georgia as a result of climate change. Environment and Ecology in the Mediterranean Region, Cambridge Scholars Publishing Book, pp. 379-393 (2012).

Mickley, L.J., D.J. Jacob and B.D. Field: Effects of future climate change on regional air pollution episodes in the United States. Geophy. Rese. Lett., 31, L24103 (2004)

Nikolaishvili, D.: Geographical Research Methods, Tbilisi, TSU(2014).

Schultz, M.G., T. Diehl, G.P. Brasseur and W. Zittel: Air pollution and climate-forcing impacts of a global hydrogen economy. Science, 302, 624-627 (2003). 